\title{
Customising Linguistics: Developing an Electronic Grammar Database for Teachers
}

\author{
Graham Lock and Amy B.M. Tsui \\ English Department, City University of Hong Kong and Department of \\ Curriculum Studies, University of Hong Kong, Hong Kong SAR, China
}

This paper considers issues in customising descriptions of English grammar in the context of creating an electronic database for secondary school teachers in Hong Kong. In developing the database, we have aimed to incorporate insights from functional grammar and corpus linguistics while keeping the information accessible and relevant to teachers familiar only with traditional approaches to grammar. This has involved exploiting the advantages of hypertext, explicitly foregrounding pedagogical concerns and developing a metalanguage that will allow discussion of areas such as transitivity and theme without alienating the teacher-users. We illustrate the kinds of compromises that are necessary in order to match the linguistic information to the needs and existing knowledge of the teacher-users.

\section{Introduction}

The relationship between linguists and second language teachers has often been problematic. To linguists, teachers sometimes seem to be operating with outdated models of language containing rules about forms and usage that owe as much to language teaching traditions as to rigorous analyses of contemporary linguistic data. To teachers, linguists can seem obsessed with the elegance of their theoretical models and determined to cloak any potentially useful insights in impenetrable terminology.

In recent years, there has been some recognition that work in both Hallidayan functional linguistics and corpus linguistics have much to offer language teachers (Celce-Murcia, 1991; Sinclair, 1991; Hasan \& Perrett, 1994; Lock, 1996; Kennedy, 1998). The former provides perspectives on the linguistic system as a resource for making meaning and on the relationships between text and context that are compatible with (or, one could even argue, essential for) communicative approaches to second language teaching. The latter enriches these perspectives with quantitative data on collocational patterns in authentic texts. At least one ESL-oriented grammar, the Collins COBUILD English Grammar (Sinclair, 1987), has been much influenced by work in both schools. However, there remains a very wide gap between information in books such as Halliday (1994), Matthiessen (1995) and Martin (1992), which, in our view, are all teeming with insights of potential value for language teachers, and the kind of information about English grammar accessible to most ESL teachers.

This paper addresses issues of customising such linguistic information in the context of developing an on-line grammar database for Hong Kong secondary school teachers. The following section provides a brief account of the background to the development of this database. 


\section{TeleNex and TeleGram}

TeleNex is a computer network established by the Teachers of English Education Centre in the Department of Curriculum Studies at the University of Hong Kong to provide a number of support services for local secondary English teachers. TeleNex encompasses two databases, one of information on English grammar (TeleGram) and one of teaching ideas (TeleTeach), as well as a range of conference corners in which teachers can ask and discuss questions about the English language and about teaching, as well as interact socially. The network started as a dial-up intranet in 1993, linking 33 secondary schools with around 380 users. It is now available for access for all school teachers in Hong Kong on the Internet. (For more detailed background information on the network and components, see Tsui et al. 1994; Tsui et al. 1996; Wu \& Tsui, 1997). This paper will be concerned with the development of the grammar database (TeleGram).

\section{Knowledge Background of Teacher-users}

Secondary English teachers in Hong Kong vary greatly in the extent to which they are subject-trained. By subject-trained, we mean teachers who have studied English linguistics in their first degree. A survey of users of the TeleNex previous to it becoming available on the Internet found that of the 328 teacher-users, about one-third had completed degrees in which they had done some kind of systematic English language study, about a quarter were non-degree holders while the remainder, the majority, had backgrounds in subjects other than English.

Most Hong Kong teachers are native speakers of Cantonese and have themselves learned English as a second language in Hong Kong. Despite the promulgation of communicative language teaching, which is frequently perceived as inimical to a focus on grammar, considerable explicit teaching of traditional English grammar still goes on in Hong Kong's schools. Textbooks without a grammar focus are not popular with teachers, and traditional reference and grammar exercise books are widely used by teachers as supplementary materials, for example, Thomson and Martinet (1986) and Murphy (1985). This means that for many non-subject-trained teachers, their knowledge about English grammar inevitably comes from the same sources as that of their students - the coursebooks they teach from and the supplementary exercises and reference books they use in class. In this, Hong Kong is no different from many other contexts (see, for example, Chalker, 1994). In other words, these teachers would have had considerable exposure to the mainstream grammatical tradition which has long informed ESL grammars and coursebooks. We shall refer to this as Traditional ESL Grammar (TEG).

The knowledge background of the teacher-users was an essential consideration in our development and presentation of the content of TeleGram. Another equally important consideration was relevance to teachers. Given the busy schedule of teachers, the database must be seen by teachers as a useful resource for classroom teaching. These two considerations have guided the aims that we laid down in the development of TeleGram, which are as follows:

1. to encourage the teachers to take a more functional and contextual view of how grammar works, 
2. to explicitly address common misconceptions and potentially misleading half-truths,

3. to develop ways of talking about aspects of grammar that are pedagogically significant but often neglected,

4. to make the information relevant to teaching English in Hong Kong.

In the rest of this paper, we shall discuss how we achieve these aims.

\section{From Traditional Grammar to Functional Grammar}

Hong Kong teachers tend to see grammar as a set of often arbitrary seeming rules for prescribing correct sentence structures. This is, of course, not unique to Hong Kong. For most classroom teachers, grammar, as Chalker (1994:31) puts it, 'is rules'.

Most ESL grammar books are still grammars of sentences with very little consideration of the relationships between grammar and context. Coursebooks used in Hong Kong do often try to present grammar in some kind of context. However, it is striking that even when an exponent of a particular structure is first presented by the coursebook in a 'passage', teachers will often focus on the structure, discuss it, analyse it and provide additional examples entirely at clause or sentence level with little or no reference to the context in which it originally appeared (Li, 1994).

Consideration of the meanings of grammatical forms and their relationships to meaning and context tends to be summed up in often rather vague rules of 'usage'. Rules of both form and usage are to be learned and applied, even when they may seem arbitrary.

The first aim of TeleGram is therefore to encourage teachers to move away from this view of grammar as rules and towards a view of grammar as a meaning-making resource. We would also like to help them develop a richer understanding of the relationships between language and context.

In achieving this aim, we were mindful that it was important not to devalue the kind of knowledge about grammar that many of the teachers already have. Moreover, to help teachers in their construction or re-conceptualisation of grammar knowledge, we must start from their existing knowledge. In particular, we wanted to avoid giving teachers a new set of terms to talk about what they may feel they have long been able to talk about quite satisfactorily in their own terms. ${ }^{2}$ While developing the content of the database, we have had to constantly make decisions about which aspects of TEG we can 'live with', which aspects can be built upon and extended in a more functional direction, and which aspects need to be challenged.

The electronic medium allowed us to organise the content in a hypertext ${ }^{3}$ format and to provide different entry points to the same set of files. The non-linear organisation of information allows users to decide at which point they wish to enter the database, what pathways to take and where to exit (see Figure 1).

The different 'ways in' to the database illustrated in Figure 1 are intended to cater for users with different kinds and levels of knowledge about grammar and different purposes for using the database while, at the same time, drawing them towards a functional view of grammar. 
Wetscape - [Grammar Datahase]

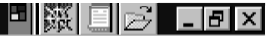

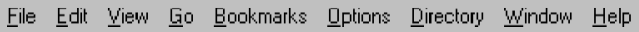

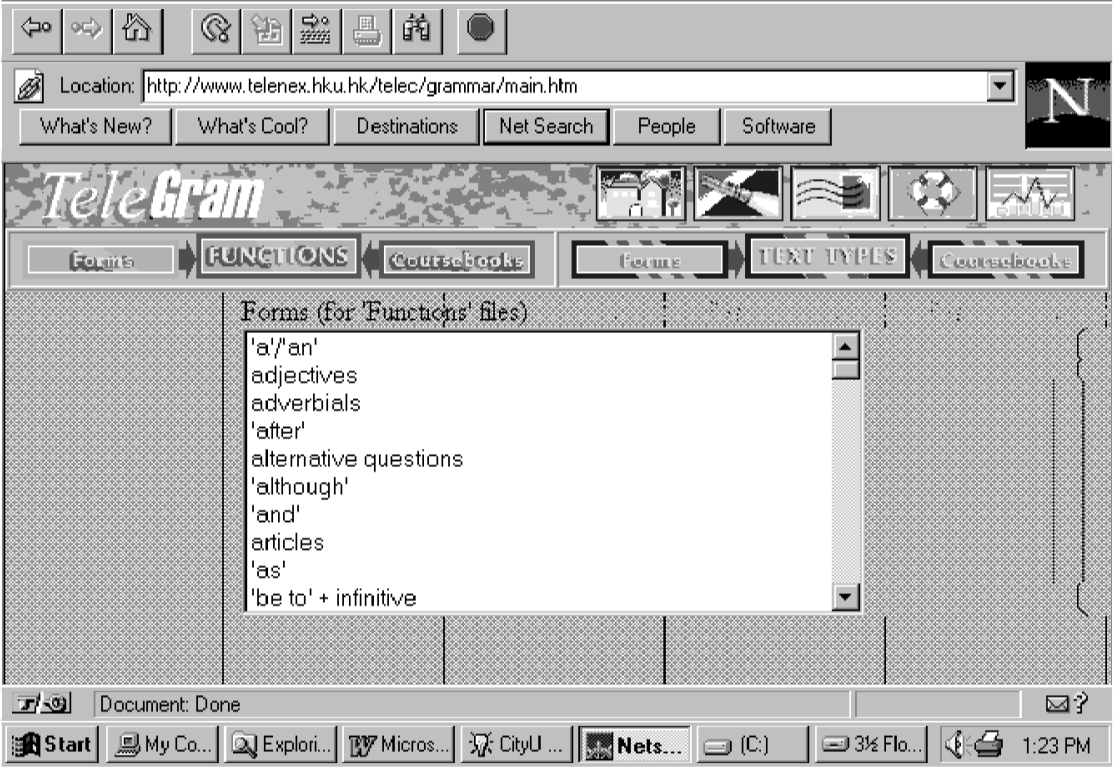

Figure 1 The initial screen of TeleGram

By clicking the Functions ${ }^{4}$ button, the user gets access to files arranged according to semantic/functional categories (see Figure 2)

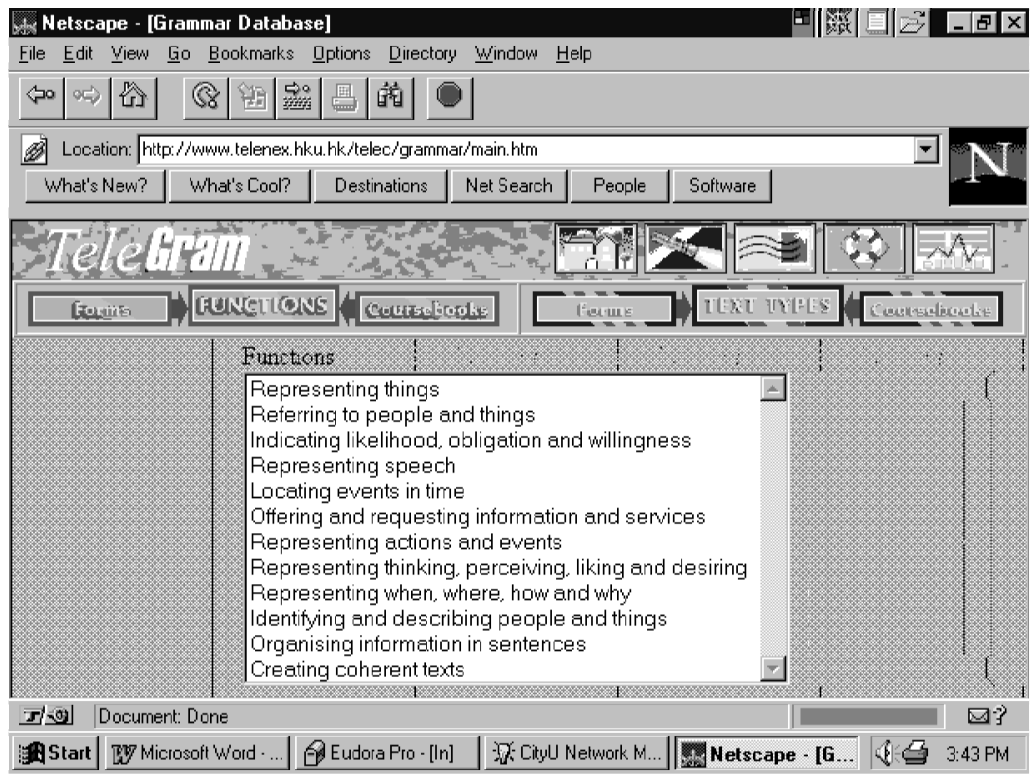

Figure 2 The Functions directory 
The organisation of files in this directory is strongly influenced by Hallidayan functional grammar. For example, files under Representing things and Referring to people and things deal with experiential and textual functions within the nominal group; files under Indicating likelihood, obligation and willingness deal with modality, files under Representing speech, Representing actions and events, Representing thinking, perceiving, liking and desiring, and Identifying and describing people and things deal with what Halliday (1994) calls verbal, material, mental, and relational processes, and files under Offering and requesting information and services deal with speech function and mood.

By clicking the Text Types button, the user gets access to files arranged according to various text-types or genres (see Figure 3).

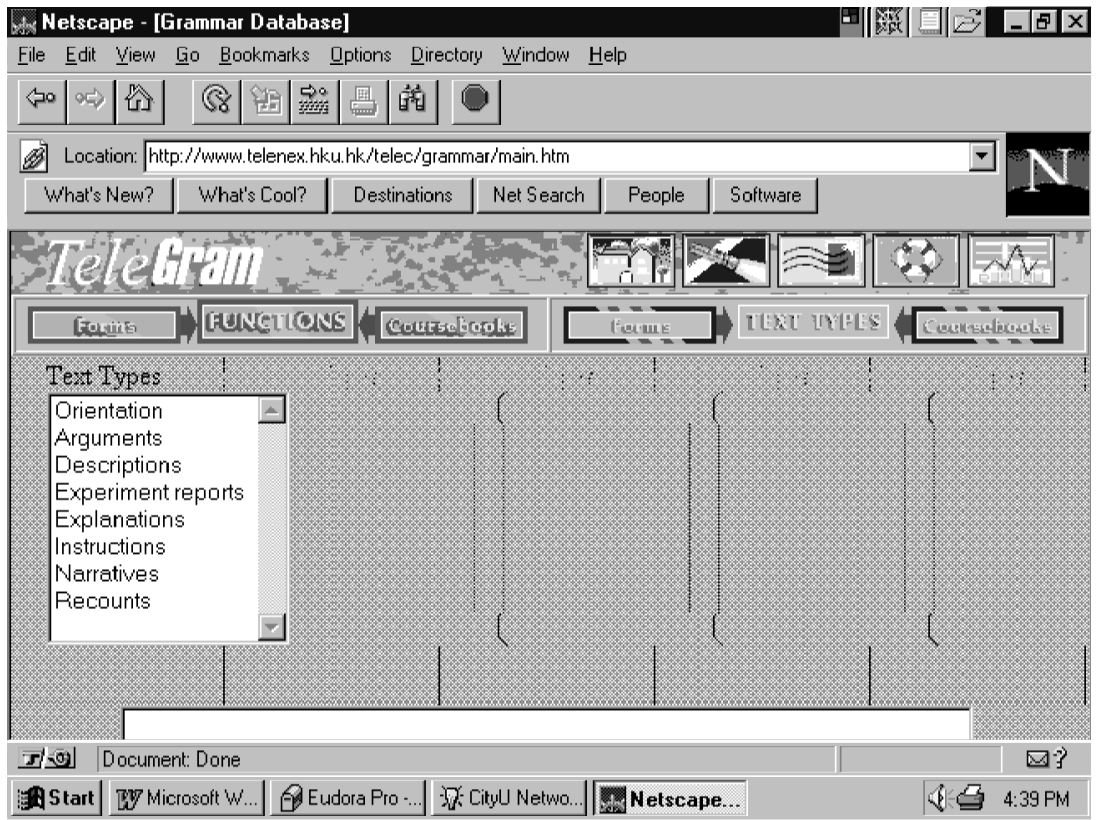

Figure 3 The Text Types directory

The current range of genres represented in this directory (and we hope to expand them later) represent text types that Hong Kong secondary students may be required to write in their English classes or whilst studying content subjects through English. The terms given to the text types in this directory are those that will be readily understood by Hong Kong teachers and they do not necessarily accord with those used in academic genre analysis.

This directory is designed to encourage users to explore relationships between grammar and context. Work done elsewhere, particularly in Australia (e.g. Cope \& Kalantzis, 1993; Christie \& Martin, 1997) suggest that genre is a good 'way in' to getting teachers and learners to consider questions of the relationships between grammar and text. Text Type files include text samples of each genre, an analysis of the schematic structure of each text, and very brief accounts of those grammatical features in the sample texts which are typically associated with the 
genre. In addition, hyperlinks have been built into these files linking them to relevant Functions grammar files, where users can get more information about grammatical features in a particular text. (See Appendix One for two sample pages from Text Type files). Similarly, hyperlinks have been built into the Functions grammar files linking them to relevant Text Type files. Thus, users can move 'down' from text to grammar and also 'up' from grammar to text. In other words, the Text Type files on the one hand provide a route into the Functions grammar files for teachers who wish to integrate a focus on grammar into lessons on, say, writing narratives, descriptions or arguments, and on the other hand provide ideas about how the teaching of, say, past tenses, adjectives or modality in a grammar lesson might be contextualised within appropriate genres.

It is the Functions and Text Types directories that map out how the writers of the files would like teachers to see the grammar of English — as systems associated with the ideational, interpersonal and textual metafunctions of language (although these terms are not used in the database) and as a resource for making meanings in texts.

However, although some teachers may also be acquainted with semantically or functionally oriented arrangements of grammatical information, for example as used in Leech and Svartvik's A Communicative Grammar of English (1994) and the Collins COBUILD English Grammar (Sinclair, 1987), we would expect most users to feel more comfortable accessing information on grammar through familiar categories like adjective or relative clause (at least initially) rather than under headings such as Representing actions and events or Arguments.

Therefore both the Functions files and the Text Types files can be accessed through directories of forms. By clicking either of the Forms buttons, the user accesses an alphabetical list of structures (e.g. relative clause, passive voice), grammatical classes (e.g. articles, adjectives) and function words (e.g. the, will) such as are used in TEG and will be familiar to many teachers. These Forms directories do not have any files uniquely associated with them. In other words, they are simply ways into the Functions or Text Type files, as indicated by the smaller size of the Forms buttons, and the arrows pointing from them to either the Functions button or the Text Types button.

For example, if a user clicks on adjectives in the Forms directory associated with Functions, a second level menu provides a number of choices such as Used to describe nouns, Used to classify nouns, Used for general reference, Used to indicate likelihood etc. If the user selects, for example, the first of these choices, he or she will see a list of files in the set $U$ sing adjectives to describe nouns, i.e. adjectives functioning as epithets in Halliday's terminology (see Figure 4).

Clicking on Overview will then take the user to the first page of the Overview file of Using adjectives to describe nouns (see Appendix 2).

Finally, users can access the files also through Coursebook directories, which enable them to locate any information in the database which is relevant to a unit of a coursebook they are teaching. This also represents another 'way in' to the Functions or Text Type files, one which will be particularly useful for teachers in a hurry to find resources relevant to an item they are about to teach.

Thus, the organisation of files within the database and the ways in which files can be accessed are designed to help users quickly locate relevant information, whatever their own grammar schema and reasons for wanting the information 


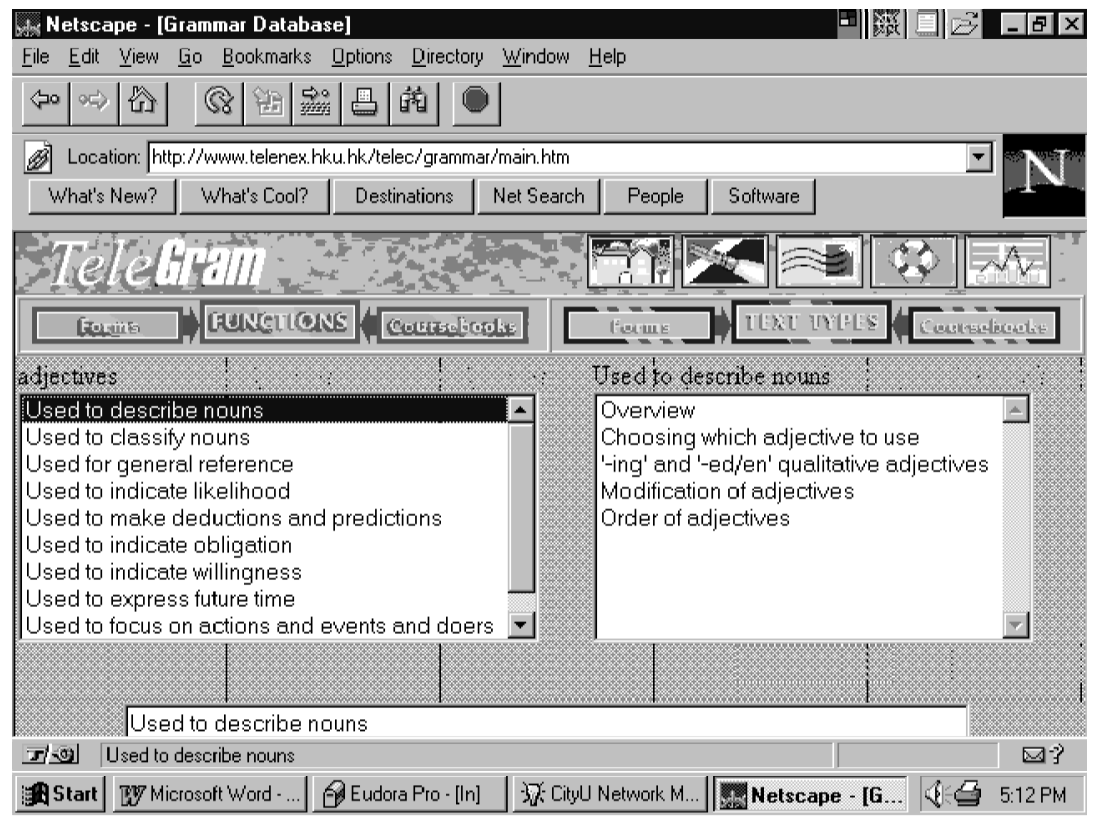

Figure 4 Files under Using adjectives to describe nouns

might be, while at the same time encouraging them to consider relationships between grammatical form and meaning and between grammar and context.

\section{Common Misconceptions and Misleading Half Truths}

Aside from their tendency to reinforce the 'grammar as rules' view, coursebooks and supplementary grammarbooks used in Hong Kong sometimes incorporate information about English grammar that represents commonly held misconceptions or potentially misleading half truths. Many of these misconceptions or half truths have been around for a long time and are by no means confined to Hong Kong.

One common example involves the 'usage rule' for the indefinite and definite articles. The rule is often stated as something like 'we use a/an when we mention things for the first time, and we use the when we mention them for the second time' (see, for example, Thomson \& Martinet $(1986: 15,19)$. One very popular Hong Kong coursebook exemplifies this with: Mary has a new sweater. The sweater is yellow. Students are then required to produce pairs such as:

John has a jacket.

The jacket has two pockets.

Carol's father gave her a pencil case.

Carol likes the pencil case very much. ${ }^{5}$

However, if we check such 'rules' against authentic language use, we will find that they are in fact misconceptions or half truths, as pronominal reference or a dependent clause would be much more likely in such contexts. The repetition of 
the noun with a definite article tends to be used only in certain conditions (see Berry, 1993). Therefore, in the development of the database, we try as far as possible to draw on the large TeleNex Textbank corpus, which consists of features articles from one of the major local English newspapers, COBUILD Direct (which can be accessed on-line) and the A and B corpora that come with the Oxford University Press Microconcord Program. (See Allan, 1999 for details of the use of corpus data in TeleNex, and Sinclair, 1991 and Stubbs, 1996 for discussions of the importance of corpus-based linguistic description).

Another example of a common misconception or half truth involves attempts to account for the use of passive voice which generally go something like: 'We use passive voice when we are more interested in the person or thing affected by the action than by the doer of the action' or 'We often prefer passive voice when it is not so important who or what did the action' or 'We use the passive when we are more interested in the action than the person who does it'. Such statements are typically accompanied by a number of single sentence examples like the following:

\section{This restaurant was built in 1958.}

\section{My letter has been opened. ${ }^{6}$}

Such statements are obviously meant to capture the fact that the use of passive voice often has the effect of thematising the goal in a clause and that the actor/agent in a passive clause can be and very often is omitted. However, it is not at all clear that either the thematised 'person or thing affected by the action' or 'the action' itself are necessarily 'what we are more interested in', particularly as the theme of a clause is typically given rather than new information (Halliday, 1994) and it is new information that the listener is presumably expected to be 'more interested in'. For example, in the first of the above sentences, the information focus would normally be on in 1958 rather than this restaurant. Nor is it clear how such a 'rule' would account for passive voice clauses in which the agent is not omitted (and is frequently the information focus).

More importantly, such vague accounts of how passive voice is used plus single sentence examples can do little to help learners see the contribution of voice selection to the flow of information in a text.

In addition, if this kind of statement of 'usage' makes any sense at all, it only does so for clauses in which some kind of 'doer' and 'person or thing affected by the action' can be identified (i.e. clauses representing what Halliday (1994) calls material processes). It can hardly apply to passive voice clauses such as she was amazed by what she heard or the flash was followed by a loud bang.

We therefore see an important role of the database as drawing teachers' attention to such misconceptions and half truths. In order to achieve this, each set of files contains one Common Misconceptions file that deals explicitly with misconceptions and half truths relevant to the area covered by the files. (See Appendix 2 for a sample page from a Common Misconceptions file.)

\section{Talking about Neglected Aspects of Grammar}

Teachers, coursebooks and learners inevitably tend to talk about those aspects of grammar that they have some shared metalanguage to talk about. This means 
that areas that ESL grammars have traditionally dealt with in detail tend to get a lot of attention, while other areas of the grammar get barely a mention. For example, TEG provides a comprehensive battery of terms for labelling the tenses of English, as well as plenty of 'usage rules' that attempt to gloss their functions in context. However, transitivity, in the Hallidayan sense of configurations of processes, participants and circumstances, is far harder to talk about, despite the fact that clause rank systems of transitivity present formidable problems for second language learners. One result is that students tend to be presented with seemingly arbitrary lists of 'transitive and intransitive verbs', 'verbs followed by the gerund', 'verbs followed by the infinitive', and so on.

Similarly, there is hardly any metalanguage in TEG for talking about the textual systems of theme/rheme and given/new, which means that these systems are not taught in any systematic way. This makes it very hard to account satisfactorily for voice choice or clefting, or to consider typical patterns of thematic development in different text types.

To find ways of talking with teachers about such aspects of grammar that are pedagogically significant but tend to be given scant attention in locally used coursebooks and reference books, we are confronted with the problem of terminology. If we confine ourselves to terms teachers are familiar with, then it will be very difficult or impossible to talk about anything new. On the other hand, nothing will put off a user more than to finally locate a file of relevant information only to find it sprinkled with unfamiliar, opaque terms. To address this problem, we have developed the following guiding principles.

First, look for an appropriate term in Hong Kong coursebooks and if necessary redefine it slightly to cover the feature we wish to refer to. If no such term can be found, look for an appropriate term in an ESL grammar reference book likely to be used in Hong Kong. Finally, if still no term can be found, either use a recognised linguistics term if there exists one that seems sufficiently transparent, or coin a term. To ensure that teachers with varying background knowledge of English grammar can understand the discussion, all technical terms are defined in a glossary provided in a 'pop-up' screen that users can access by clicking on the glossary icon.

Terminology is not, of course, theoretically neutral. Application of the principles outlined above sometimes lead to compromises that linguists might be uncomfortable with. One example is the distinction between the nominal group functions of epithet (typically realised by adjectives) and classifier (typically realised by both adjectives and nouns). This distinction is not consistently made in coursebooks and there are no terms exactly corresponding to it (partial information on classifiers tends to turn up under rubrics such as 'using nouns as adjectives'). We felt that the functional linguistics term classifier was sufficiently transparent, and so we have adopted it. However, the term epithet would not be at all transparent to most of the potential users of the database. The COBUILD grammar, which is known to some teachers in Hong Kong, does in fact make a distinction between qualitative adjectives and classifying adjectives. Qualitative adjectives maps fairly well onto epithets, as epithets are normally realised only by adjectives. We therefore used the term qualitative adjective in the file on Using adjectives to describe nouns. This is not an ideal solution, as it suggests that qualitative 
adjectives are a sub-class of adjective rather than one of the functions that adjectives can have. It is, however, a term that is not as alien or opaque to teachers as epithet.

Another example involves the difficult area of transitivity. From the Hallidayan perspective, systems of transitivity are clause rank systems which express the experiential meaning of clauses as configurations of processes, participants and circumstances. Even at a fairly low level of delicacy, analyses of transitivity require an array of labels for the various kinds of participant roles associated with different process types.

We addressed this problem by using technical terms for participant roles only when absolutely necessary and making them as transparent as possible when we did need to use them. In many cases, participant roles could simply be glossed where they needed to be referred to. For example, in discussing clauses such as I'll send you a letter and I'll draft you a letter, we found it adequate to gloss the participant role of you in these two clauses as either 'the person who will be the receiver of the direct object (the letter)' or 'the person who benefits from the letter having been drafted'. There was no need to introduce a technical term such as beneficiary, still less terms representing the more delicate distinction between client and recipient (Halliday, 1994). However, in a fairly detailed discussion of mental processes clauses, which on the whole present much greater problems for learners, we found we did need some terms for participants to avoid having to repeat circumlocutions many times. We finally decided on the four terms thinker, feeler, desirer and perceiver. Note that in this case, for the sake of transparency, we in fact make more participant role distinctions than Halliday, who generalises a single participant role (senser) for these four.

In dealing with transitivity in the database, we also had to make decisions about how to talk about the central Hallidayan notion of process type. Most teachers see transitivity as a property of the verb, and they are familiar with the notions of transitive and intransitive verbs. Some are also familiar with a limited number of semantically-based 'verb types', such as 'verbs of perception' and 'reporting verbs', and with 'verb patterns' associated with different verb types. We have made use of these notions of 'verb types' and 'verb patterns' and tried to extend them to a broader consideration of process types. For example, within the area Representing thinking, perceiving, liking and desiring can be found files with names like Using verb patterns to represent perceptions, Using verb patterns to represent likes and dislikes and Using verb patterns to represent desires and hopes.

There is of course a cost in accepting (at least initially) the notion of transitivity as a property of the verb. We find ourselves having to say things such as 'have when used as a possession verb cannot normally be used with continuous tenses' or 'feel can be used both as a linking verb and an action verb'. However, we see no alternative to this if we are not to alienate teachers from the database.

\section{Pedagogical Relevance}

As mentioned above, most users of the database are busy classroom teachers who are likely to make use of the database only to the extent that it meets their professional needs, that is, it provides them with information useful for planning lessons, presenting grammar in the classroom, answering students questions, understanding students mistakes and so on. 
To make the database pedagogically relevant to teachers, we were selective in the areas that we concentrated on. For areas that are covered reasonably well in coursebooks and seem to present fewer problems for teaching, for example differences between common nouns and proper nouns, and irregular plural forms, we dealt with only briefly. We identified areas in which a functional perspective seemed likely to offer something that was lacking in most locally used materials. For example, in preparing files on the nominal group (listed under the rubrics Representing things and Referring to people and things) we first investigated the ways this area is treated in a number of locally used textbooks, and identified gaps that needed to be filled. The following are some examples of how we filled these 'gaps':

- an account of nominalisation that goes beyond discussions of the 'gerund' and a few suffixes used to derive nouns from verbs to seeing nominalisation as a kind of grammatical metaphor much exploited in the language of the content subject areas that students study (Halliday \& Martin, 1993)

- an account of (pre)modification that goes beyond word class (and such clumsy notions as 'using nouns as adjectives') to recognising important functional constituents of the nominal group, such as epithet and classifier.

- an account of reference that goes beyond the usual long list of rules for article usage exemplified with decontextualised sentences to looking at how determiners and pronouns are used to track participants in texts, and how they relate to other cohesive devices.

Apart from focusing on selective areas, we have also sought to foreground pedagogical concerns in various ways. Each set of files contains a number of pedagogically oriented files, including Common Misconceptions, Teaching Implications and Students' Problems. Common Misconceptions files have already been described above. Teaching Implications files suggest ways in which the teaching of the relevant grammar points might be approached in the classroom. Hyperlinks to specific files in TeleTeach, a teaching resources database, have also been built in. These files provide ideas on how a specific grammar area can be taught. Student Problems files discuss difficulties learners may have in the relevant area. Authentic examples of students' mistakes are taken from a corpus of student writing which is still building, TeleNex Student, covering all secondary levels.

\section{Teachers' Feedback}

In developing a resource such as TeleGram, it is of course important to take into account feedback from the teacher-users. One way we do this is through a Comments button, which allows users to send in suggestions and opinions that can be used in revising the files. We also carried out a small scale study of teachers' reactions to the Intranet version of the database (i.e. before the database was made available on the Internet). In this study, two groups of teachers were asked to do two different directed tasks. One group, consisting of 13 teachers, was asked to read a typical set of TeleGram files, complete an evaluation questionnaire and attend semi-structured interviews. Another group, consisting of 12 teachers, was asked to read another set of files and write down their reactions freely.

Teachers in the first group were asked to compare the information presented in TeleGram with that in reference grammars. 12 out of the 13 teachers rated Tele- 
Gram very useful or useful, whereas only 10 of the teachers rated reference grammars as useful. In an open-ended question, most of the teachers described the grammatical information presented in TeleGram in positive terms, using adjectives such as 'practical', 'useful', 'up-dated', 'simple' and 'easy to digest'. By contrast, some teachers described reference grammars as 'mainly explain(ing) grammatical patterns/rules' and 'sometimes too long (and) contain(ing) too many technical terms/jargons which are not easy to understand'. When the teachers were asked to evaluate each file of the set, they rated Students' Problems as the file that they liked best. They also rated the Teaching Ideas ${ }^{7}$ file very highly.

Many teachers in the second group described the database as practical and informative and said that the systematic presentation of grammatical information helped them to organise their teaching. They liked the use of authentic examples in the discussion, though they would welcome more, and the clarity of the explanations. Like the first group of teachers, they liked the Students' Problems file best and referred to the database as a good teaching tool.

The following written comment made by one teacher summarises quite well the comments made by most of the teachers:

I find it useful because they (the files) are very informative and practical. The files offer all possible explanations to the usage. Although they may not all be useful to the students, the teachers are free to choose what is applicable to their students. Next the layout, 'Prof's Quiz', 'Ways of expressing comparison', 'Misconceptions' ... helps teachers to be more systematic as well because very often, when I need to teach a grammar item, I may not think in a systematic way. The Telenex [TeleNex] helps us to be better organised. Time is also saved, e.g. instead of thinking what kind of common errors students usually make, what I need to do is just to press the button and I'll have them before me ... In short, I like this program: it is easy to use; and instead of looking up different reference books or grammar books, figuring out what to include in my lesson, I can do it easily now. It's like an encyclopaedia for grammar teaching.

\section{Concluding Remarks}

Any pedagogical grammar, whether intended for learners or for teachers, inevitably represents a compromise between such factors as linguistic accuracy and theoretical coherence on the one hand and explanatory simplicity and pedagogical relevance on the other (seeSwan, 1994 for discussion of design criteria for pedagogical rules). In customising linguistic information for ESL teachers in Hong Kong, TeleGram has faced the same problems as all pedagogical grammars. We have tried to address these problems by taking as much account as possible of knowledge the users may already have and by keeping unfamiliar technical terminology to a minimum. At the same time, we have tried to help teachers re-conceptualise their grammar knowledge by introducing new perspectives and dimensions on the basis of their existing knowledge. We have also concentrated on selective areas which are likely to be most relevant to the users and foregrounded their pedagogical concerns throughout. We would argue that the inevitable compromises that we have made are necessary if the important new 
insights about how the English language works provided by linguistics are to be made available and accessible to language teachers.

\section{Acknowledgements}

This project has been funded by the Hong Kong Telecom Foundation, the Hong Kong Government Language Fund and the Hong Kong Jockey Club in the past five years. The research side was funded by the Research Grants Council of the University Grants Committee, Hong Kong. The authors wish to thank the funding bodies for their generous support.

\section{Correspondence}

Any correspondence should be directed to Graham Lock, English Department, City University of Hong Kong, Tat Chee Avenue, Kowloon, Hong Kong SAR, China (englock@cityu.edu.hk).

\section{Notes}

1. The Web address of TeleNex is http://www.telenex.hku.hk.

2. The political danger of this can be seen in the Australian experience, in which an attempt to introduce a modified functional grammar into the school curriculum was publicly criticised.

3. Whalley (1993) points out that it is difficult to frame a formal definition of 'hypertext', which is very much an evolving medium. He suggests that an adequate working definition would be 'machine-supported links between blocks of text and some measures of interaction by the reader' (p. 8). In other words, users can jump from one block of text to another if a link has been built in by the computer.

4. Although form versus function is something teachers are familiar with (many coursebooks have a list of forms and functions in their contents pages), it represents a dichotomy we were not altogether happy with. In addition, the term 'function' as it is used in TESL has come to mean little more than a list of possible uses of language. We originally used the label 'making meanings' and then 'expressing meanings' for this directory. However, teachers we talked to liked neither of these labels and 'function' does at least have the virtue of signalling some kind of orientation to language as communication.

5. The examples are taken from English Today: A Modern Course. Aristo Educational Press. Hong Kong (1996).

6. Also from English Today: A Modern Course.

7. In the Intranet version, each file contains a section called Teaching Ideas in which activities and materials for teaching were provided. In the Internet version, a hyperlink has been built in which takes the user to the relevant part of TeleTeach.

8. The file that the teacher was commenting on was on Comparison.

\section{References}

Allan, Q.G. (1999) Enhancing the language awareness of Hong Kong teachers through corpus data: The TeleNex experience. Journal of Technology and Teaching 7 (1), 57-74.

Berry, R. (1993) Collins COBUILD English Guides 3: Articles. London: HarperCollins.

Celce-Murcia, M. (1991) Grammar pedagogy in second and foreign language teaching. TESOL Quarterly 23 (3), 459-479.

Chalker, S. (1994) Pedagogical grammar: Principles and problems. In M. Bygate, A. Tonkyn and E. Williams (eds) Grammar and the Language Teacher (pp. 31-44). Hemel Hempstead: Prentice Hall.

Cope, W. and Kalantzis, M. (eds) (1993) The Powers of Literacy: A Genre Approach to Teaching Literacy. London: The Falmer Press. 
Christie, F. and Martin, J.R. (eds) (1997) Genre and Institutions: Social Processes in the Workplace and School. London and Washington: Cassell.

Halliday, M.A.K. (1994) An Introduction to Functional Grammar (2nd edn). London: Edward Arnold.

Halliday, M.A.K. and Martin, J.R. (1993) Writing Science: Literacy and Discursive Power. London: The Falmer Press.

Hasan, R. and Perrett, G. (1994) Learning to function with the other tongue: A systemic functional perspective on second language teaching. In T. Odlin (ed.) Perspectives on Pedagogical Grammar (pp. 179-226). Cambridge: Cambridge University Press.

Kennedy, G.D. (1998) An Introduction to Corpus Linguistics. London and New York: Longman.

Leech, G. and Svartvik, J. (1994) A Communicative Grammar of English (2nd edn). London and New York: Longman.

Li, V.L.H. (1994) A descriptive study of how grammar is taught at the intermediate level in secondary schools in Hong Kong. Unpublished MA dissertation, English Department, City University of Hong Kong.

Lock, G. (1996) Functional English Grammar: An Introduction for Second Language Teachers. Cambridge: Cambridge University Press.

Martin, J.R. (1992) English Text: System and Structure. Philadelphia and Amsterdam: John Benjamins.

Matthiessen, C. (1995) Lexicogrammatical Cartography. Tokyo: International Language Sciences Publishers.

Murphy, R. (1985) English Grammar in Use: A Self-study Reference and Practice Book for Intermediate Students. Cambridge: Cambridge University Press.

Sinclair, J. McH. (ed.) 1987 Collins COBUILD English Dictionary. London: HarperCollins.

Sinclair, J. McH. (1991)Corpus, Concordance, Collocation. Oxford: Oxford University Press.

Stubbs, M. (1996) Text and Corpus Analysis. Oxford: Blackwell.

Swan, M. (1994) Design criteria for pedagogic language rules. In M. Bygate, A. Tonkyn and E. Williams (eds) Grammar and the Language Teacher (pp. 44-55). Hemel Hempstead: Prentice Hall.

Thomson, A.J. and Martinet, A.V. (1986) A Practical English Grammar. Oxford: Oxford University Press.

Tsui, A.B.M., Coniam, D., Sengupta, S. and Wu, K.Y. (1994) Computer-mediated communications and teacher education - the case of TeleNex. In N. Bird, P. Falvey, A.B.M. Tsui, D.M. Allison and A. McNeill (eds) Language and Learning (pp. 352-369). Hong Kong: Government Printer.

Tsui, A.B.M., Wu, K.Y. and Sengupta, S. (1996) Enhancing teacher development through TeleNex. System 24 (4), 461-476.

Wu, K.Y. and Tsui, A.B.M. (1997) A teachers' grammar on the electronic highway. System 25 (2), 169-183.

Whalley, P. (1993) An alternative rhetoric for hypertext. In C. McKnight, A. Dillon and J. Richardson (eds) Hypertext - A Psychological Perspective (pp. 17-18). New York: Ellis Horwood. 


\section{Appendix 1: Sample Pages from Text Type Files}

\section{Descriptions}

\section{Organisation of descriptions}

\section{Structural analysis of Amazing mammals}

The comments about structure in this analysis are organised as follows: the main stages are in CAPITALS; elements within each stage are in italics (and indented) $\mathbf{N D}$.

\section{Amazing mammals}

Mammals are warm blooded and furred, and almost all give birth to their young alive and suckle them.

\section{IDENTIFICATION W]} definition

There are three groups of mammals - marsupials, monotremes and placentals.

classification

In Australia, marsupials are by far the most prominent. They give live birth, but their young are not fully developed, and are kept in a pouch until

DETAILS of $1^{\text {st }}$ sub-class (marsupials) distribution and behaviour

they develop enough to move around independently.

Kangaroos, possums and wallabies are examples of Australian marsupials.

Monotremes are probably the most exotic type of mammals.

Rather than giving birth to live young, they lay eggs. However, they do suckle their young and display other mammalian traits.

The duck-billed amphibious platypus is a monotreme, as is the echidna or spiny anteater.

DETAILS of $2^{\text {nd }}$ sub-class (monotremes) general statement

behaviour

examples

\section{DETAILS of $3^{\text {rd }}$ sub-class (placentals)} distribution

example

The native dog, the dingo, is a member of the placental group but naturalists are of the opinion that it might be an introduced species.

(Jarratt, P. (ed) (1985) Australia. APA Productions.)

\section{Introduction}

Structural analysis of Amazing mammals

Structural analysis of Structure and functions of the eye

Structural analysis of Yixing 


\section{Appendix 1 (cont.)}

\section{Descriptions}

Using linking verbs to identify and describe things

page 2 of 9

\section{Equating things}

Iden tifying clauses 6 equate one noun group with another noun group. They are often used in general descriptions (particularly technical and semi-technical descriptions) to define the things being described and to give examples of them:

The eye is the sensory organ responsible for sight.

(Structure and functions of the eye)

Kangaroos, possums and wallabies are examples of Australian marsupials. (Amazing manmais)

Note that such clauses are normally reversible:

The eye is the sensory organ responsible for sight.

$\overrightarrow{T h}$ sensory organ responsible for sight is the eye.

Kangaroos, possums and wallabies are examples of Australian marsupials.

$\overrightarrow{E x a m p l e s ~ o f ~ A u s t r a l i a n ~ m a r s u p i a l s ~ a r e ~ k a n g a r o o s, ~ p o s s u m s ~ a n d ~ w a l l a b i e s . ~}$

For further information about linking verbs, see Representing being and having: Using linking verbs.

Introduction

Equating things

Putting things into classes and describing their qualities

Giving information about location

Waying what things possess or consist of

Norder between linking verbs and passives

Wsing linking verbs in Amazing mammals

Using linking verbs in Structure and functions of the eve

Using linking verbs in Yixing 


\section{Appendix 2: Sample Pages from Files on Qualitative Adjectives (top) and from a Misconceptions File (bottom)}

\section{Using adjectives to describe nouns}

Ad Overview

page 1 of 4

\section{Introduction}

Vouns often have in front of them adjectives or other nouns which modify their meaning in some way, for example a large Egytian statue, a college sports centre and a new scientific theory.

Some adjectives like Egyptian and scientific, as well as nouns such as college and sports, function to subclassify the noun in some way. Such words are known as classifiers.

Other adjectives like large and new function to describe a certain quality that the noun has. They are known as qualitative adjectives $[\boldsymbol{\sigma}]$. This file provides an overview of qualitative adjectives.

You may either read through the file page by page or jump to a specific page by clicking on one of the choices below.

For further information about classifiers, see $\boldsymbol{Q}$ Using adjectives and nouns to classify nouns: Overview.

Introduction

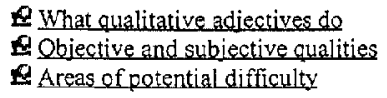

Copyright (1) 1998 TELEC. All rights reservad.

Using passive voice

K Misconceptions

puge 2 of 4

Why we use passive voice

Many coursebooks and grammar books explain the use of passive voice along the lines of "passive voice is used when we are more interested in the receiver of an action than the docr of an action". Such an explanation is not entirely wrong, but can be misleading, as it is not elear what "more interested in" means. In fact, when passive voice is used, it can often be the verb itself or even the agent [or (or "doer") which is emphasised:

There were several who wanted George to be President but the Communists kept thetr word and blackened him. George was defeated. (Bank of English)

In the November election, Evans was defeated by a man who'd been dead for three months. (Bank of English)

For further information about this, see Using oassive voice: What is passive voice for? and $\mathrm{A}$ Using passive voice: Passive voice in context.

\footnotetext{
$\mathbf{Z}$ Introduction

Why we use passive voice

2 Passive voice with non-action verbs

$Z$ Passive voice with intransitive verbs
} 